\title{
Properties of alumina-based ceramic cores
}

\author{
*Xiao-fu Liu, Xin-li Guo, Guo-yan Shui, Chang-chun Li, Gui-qiao Su, Xun Sun, Yang Guan, Lei Jin \\ Shenyang Research Institute of Foundry Co., Ltd., Shenyang 110022, China
}

\begin{abstract}
Fused corundum is a rather promising raw material for preparing an alumina-based ceramic core due to its excellent high temperature resistance and chemical inertness. In this study, alumina-based ceramic cores were prepared using fused corundum as the matrix material, and the effect of varying silica powder contents on the properties of the alumina-based ceramic cores, including the sintering shrinkage, the flexural strength, and the high temperature deformation was investigated. The mineralization mechanisms of the silica on the alumina-based ceramic core were also analyzed. The optimum addition amount of silica in this experiment is $8 \%$ in weight. At that moment, the aluminum-based core has both a low sintering shrinkage coefficient of $0.66 \%$ and better properties: the room temperature flexural strength is $22.19 \mathrm{MPa}$, the high temperature flexural strength is $21.54 \mathrm{MPa}$, the high temperature deformation is $0.93 \mathrm{~mm}$, and the residual flexural strength is $47.41 \mathrm{MPa}$.
\end{abstract}

Key words: fused corundum; ceramic core; mineralization mechanism; silica powder

CLC numbers: TG221 ${ }^{+} .1$

Document code: A

Article ID: 1672-6421(2021)06-593-06

\section{Introduction}

Directionally solidified (DS) or single-crystal (SC) superalloy hollow blades are the key components of aero-engines and gas turbines, and the ceramic cores are the transition components used to form the cavity of the blades ${ }^{[1-4]}$. The performances of the ceramic cores directly affect the dimensional accuracy and the yield of the hollow blades, and the manufacturing technologies of the cores are generally classified as secret ${ }^{[5]}$. The ceramic cores used for the superalloy hollow blades are mainly silica-based and the alumina-based, and the corresponding matrix materials are quartz glass and fused corundum, respectively. Compared with the silica-based ceramic core, the alumina-based ceramic core possesses higher refractoriness, chemical inertia, high temperature strength and creep resistance, presenting favorable development and application prospects ${ }^{[6-7]}$. However, there are still some problems with the alumina-based ceramic cores, such as high sintering shrinkage coefficient, low flexural strength, and poor creep resistance at high temperature ${ }^{[8]}$.

To solve the above problems, key parameters affecting the properties of the alumina-based ceramic cores with silica as mineralizer were studied, including

\section{*Xiao-fu Liu}

Male, born in 1979, Ph.D., Senior Engineer. His research interests mainly focus on investment casting technologies of superalloys.

E-mail: liuxf-01@163.com

Received: 2021-07-01; Accepted: 2021-12-03 the sintering shrinkage coefficient, flexural strengths, the deformation at high temperature, and the thermal expansion property. The mineralization mechanism of silica on the alumina-based ceramic core was also discussed, with the aim to provide technical support for the development of the alumina-based ceramic cores.

\section{Experimental procedure}

Fused corundum with 325 mesh granularity was used as matrix material, and silica powder with 400 mesh granularity was used as the mineralizer. The chemical compositions of the fused corundum and the fused silica are shown in Table 1. The median diameter of the fused corundum is $35.95 \mu \mathrm{m}$, and its particle size distribution is shown in Fig. 1. The median diameter of the silica is $10.81 \mu \mathrm{m}$, and its particle size distribution is shown in Fig. 2. The mixture of paraffin, beeswax and polyethylene with the proportion of 93:5:2 (weight ratio) was used as plasticizer. Silicon oil was used as release agent.

The corundum, silica powder and the plasticizer were heated at $100{ }^{\circ} \mathrm{C}$ and mixed to obtain a uniform ceramic slurry with the WJ1.1 mixer, and then, the mixture was formed into ceramic cores using the hotpress method. The addition amount of plasticizer was $16 \%$ (weight percent unless otherwise stated) of the total powder, and the silica accounted for $4 \%, 8 \%, 12 \%$, $16 \%$ and the corresponding ceramic cores were marked SA-1, SA-2, SA-3, SA-4, respectively. The sintering temperature was $1,350{ }^{\circ} \mathrm{C}$. 
Table 1: Chemical composition of fused corundum and silica (wt.\%)

$\begin{array}{ccccccccc}\text { Materials } & \mathrm{Al}_{2} \mathrm{O}_{3} & \mathrm{SiO}_{2} & \mathrm{Fe}_{2} \mathrm{O}_{3} & \mathrm{Na}_{2} \mathrm{O} & \mathrm{K}_{2} \mathrm{O} & \mathrm{CaO} & \mathrm{MgO} \\ \text { Fused corundum } & 99.59 & 0.081 & 0.036 & 0.085 & 0.048 & 0.049 & 0.021 \\ \text { Fused silica } & 0.001 & 99.69 & 0.033 & 0.001 & 0.001 & 0.078 & 0.001\end{array}$

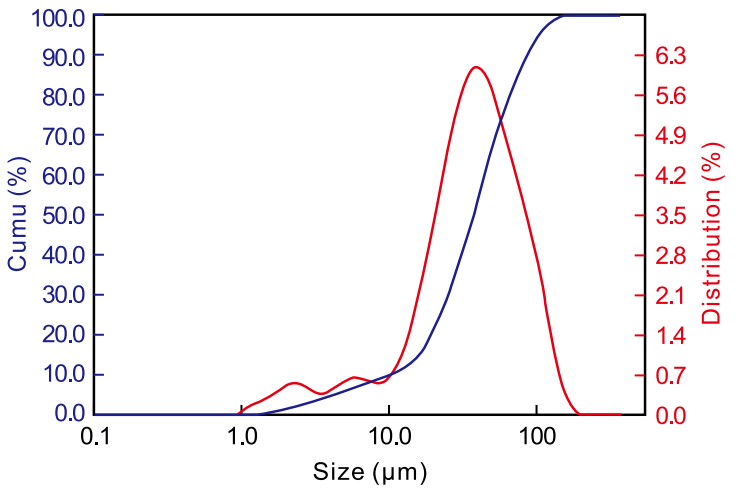

Fig. 1: Particle size distribution of fused corundum powder

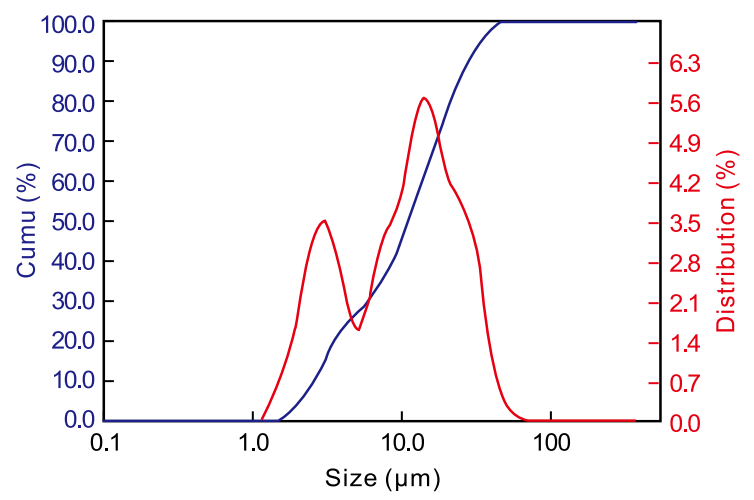

Fig. 2: Particle size distribution of silica powder

The bending strength, sintered shrinkage and thermal deformation of the ceramic cores were tested according to relevant aviation industry standards: HB 5353.3-2004, HB 5353.2-2004, and HB 5353.4-2004.

A WDW-20 flexural strength meter was used to measure the flexural strengths of the core specimens at room temperature and $1,550{ }^{\circ} \mathrm{C}$, a DJ-2000 g/0.01 g electronic scale was used to measure the apparent porosities and the bulk densities, and a S-3400N Hitachi scanning electronic microscope was used to observe the fracture morphologies of the core specimens.

\section{Results and discussion}

\subsection{Effects of silica content on sintering shrinkage of alumina-based ceramic core}

It can be seen from Fig. 3 that the sintering shrinkage of the alumina-based ceramic cores firstly decreases and then increases with the increase of the silica contents. The sintering shrinkage is the minimum of $0.66 \%$ at the silica content of $8 \%$, and the maximum of $1.01 \%$ at the silica content is $16 \%$. The shrinkage process during sintering is a migration process of

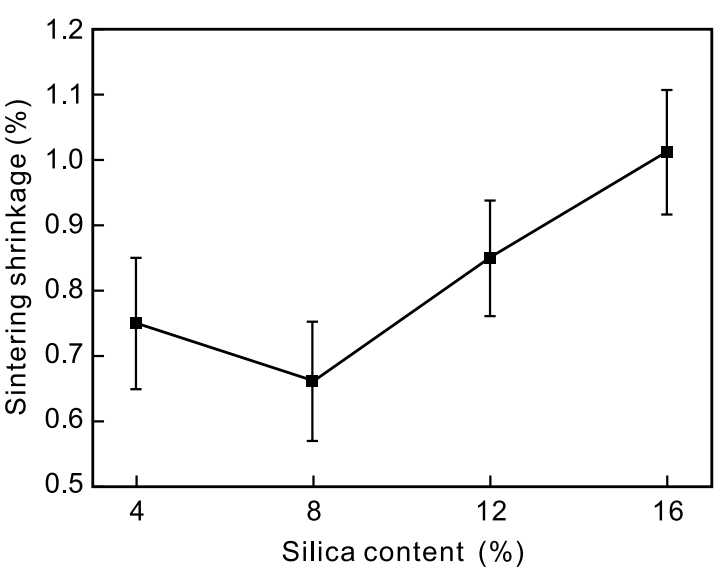

Fig. 3: Sintering shrinkage of alumina-based cores

the granular materials. The granular materials migrate toward the neck region of the bridge between two granules through the surface diffusion and the crystal lattice diffusion, enabling the sintering bridge neck to be filled continuously and the gap between the ceramic granule centers to be closed, resulting in shrinkage of the ceramic on a macro level. In addition, the more the glass phase content, the greater the sintering shrinkage. In contrast, the more the mullite phase, the less the shrinkage as the forming of the mullite phase is an expansion process. Silica is not only an ingredient of forming the glass phase in the alumina-based ceramic core, but also can form mullite phase. When its content is small, the formed glass phase and mullite phase at high temperature will be small, therefore the sintering shrinkage is small comparatively; vice versa, when its content increases, both the glass phase and mullite phase at high temperature increase, the content of alkali metal impurities will also increase accordingly, and too many alkali ions will hinder the formation and growth of mullite. So, the most suitable silica content is such that a small amount of glass phase and a great amount of mullite phase are formed. When the silica content is $4 \%$, both the glass and the mullite phase contents are less, and the sintering shrinkage is relatively smaller. When the silica content increases to $8 \%$, the increase of the mullite phase will counteract the shrinkage effect of the glass phase, so the sintering shrinkage decreases. When the silica content further increases to $12 \%$ and $16 \%$, the glass phase shrinkage effect is greater than the mullite phase expansion effect, the sintering shrinkage obviously increases. Figure 4(a) shows the microstructure of the SA-2 ceramic core, where a lot of mullite phase is found in the glass phase. Figure 4(b) shows the microstructure of the SA-3 ceramic core, where although a certain amount of mullite phase is found, the glass phase content is also high. 

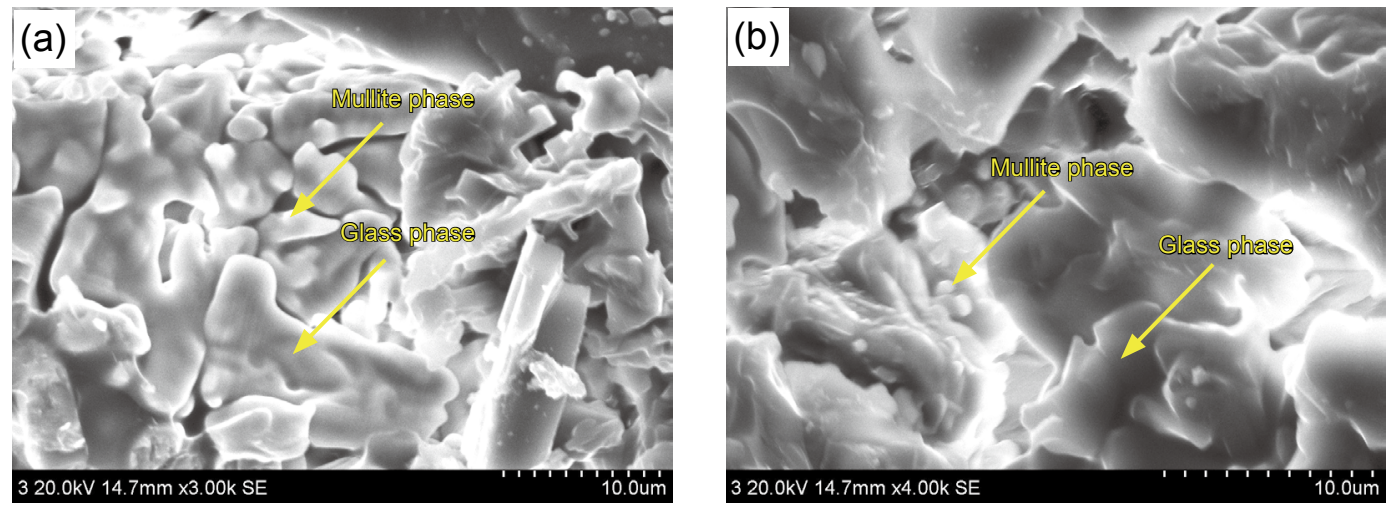

Fig. 4: Microstructures of SA-2 (a) and SA-3 (b) ceramic cores

\subsection{Effects of silica content on room temperature flexural strength of alumina- based ceramic core}

The room temperature flexural strength of the alumina-based ceramic cores firstly decreases, then increases, and decreases again with the increase of the silica contents, as shown in Fig. 5. When the silica content is $12 \%$, the room temperature flexural strength reaches the maximum of $26.29 \mathrm{MPa}$. When the silica content is $16 \%$, the room temperature flexural strength is the minimum of $20.08 \mathrm{MPa}$.

The fracture morphologies of the alumina-based ceramic cores with different silica contents are shown in Fig. 6. It can be seen that the fracture mechanisms of the four samples are all brittle ruptures along the glass phases. The glass phases are connected as a whole with a great number of holes distributed in it.
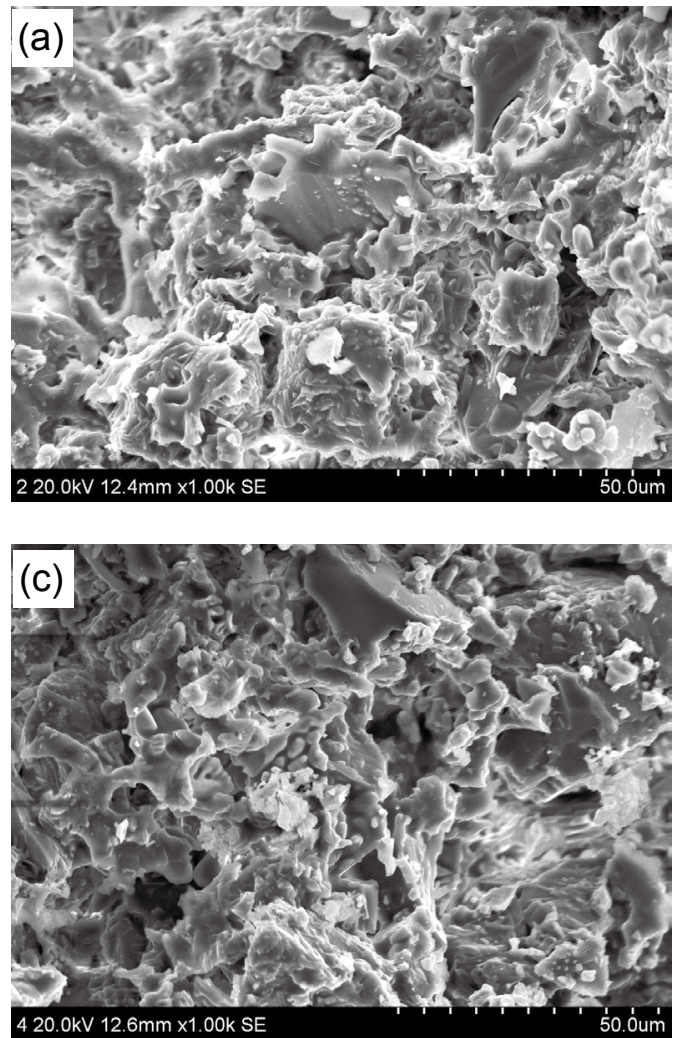

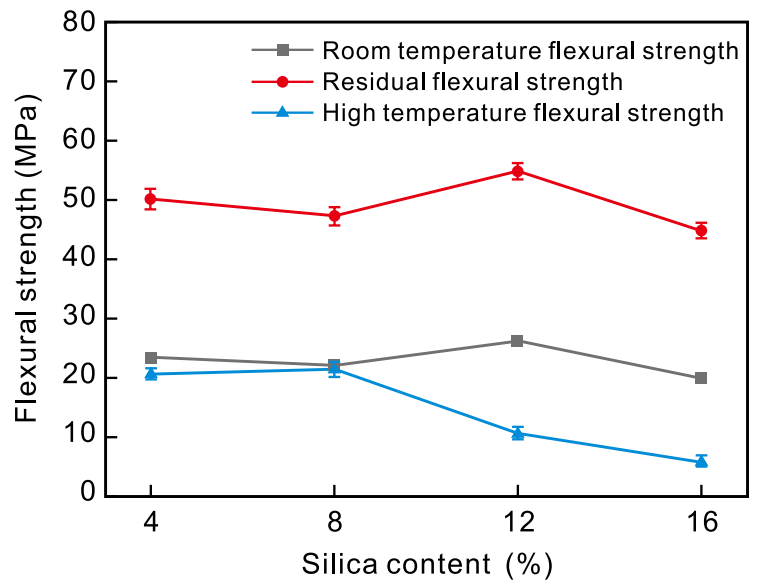

Fig. 5: Flexural strengths of aluminum-based ceramic cores depending on silica contents
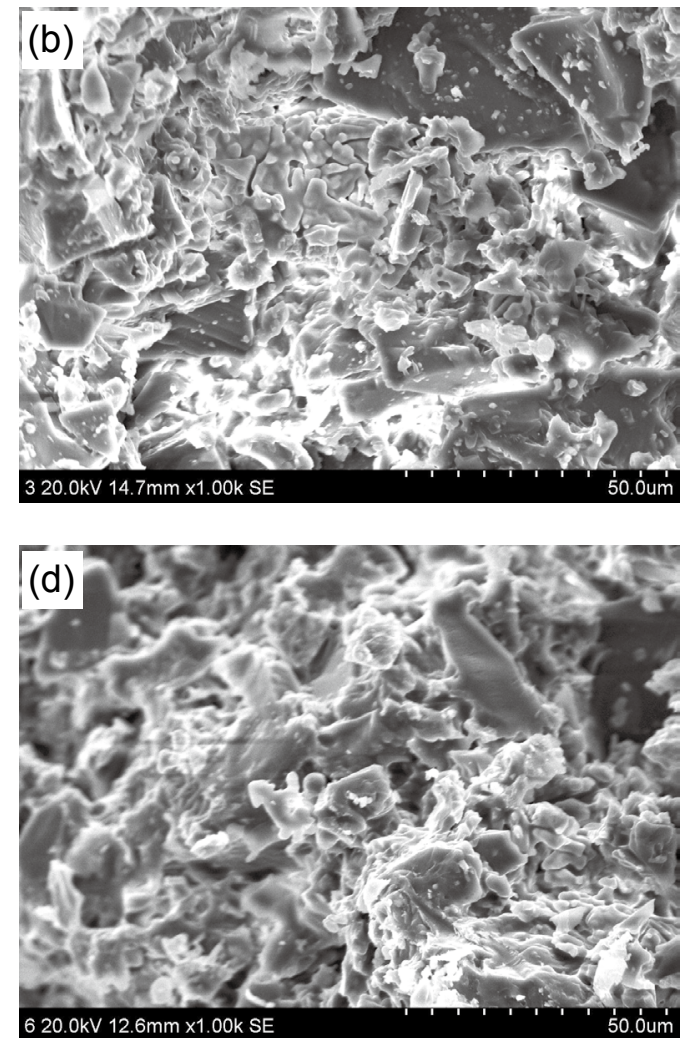

Fig. 6: SEM fracture morphologies of ceramic cores sintered at $1,350^{\circ} \mathrm{C}$ : (a) SA-1; (b) SA-2; (c) SA-3; (d) SA-4 


\subsection{Effects of silica content on high temperature flexural strength and deformation of alumina-based ceramic core}

As shown in Fig. 5, the high temperature flexural strength of the alumina-based ceramic cores firstly increases slowly from 20.73 MPa to $21.54 \mathrm{MPa}$ with the increase of the silica content from $4 \%$ to $8 \%$, and then sharply decreases to $10.78 \mathrm{MPa}$ when the silica content further increases to $12 \%$, decreasing a half. When the silica content further increases to $16 \%$, the high temperature flexural strength of the core decreases to 5.99 MPa. This indicates that excessive silica will decrease the high temperature flexural strength of the alumina-based ceramic core rapidly.
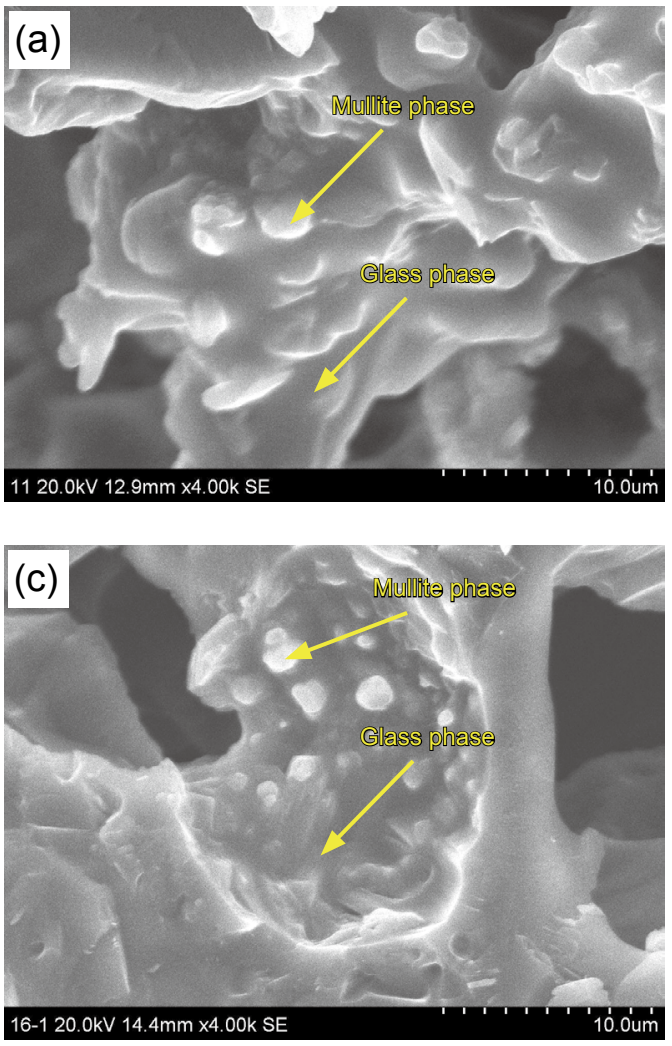

Fig. 7: SEM fracture morphologies of ceramic cores after high temperature testing: (a) SA-1; (b) SA-2; (c) SA-3; (d) SA-4

The high temperature deformation of the alumina-based ceramic cores firstly decreases slightly and then sharply increases with the increase of the silica content, as shown in Fig. 8, indicating that excessive silica content will degrade the high temperature deformation resistance of the cores. When the silica content is $8 \%$, the high temperature deformation of the core is the minimum of $0.93 \mathrm{~mm}$.

\subsection{Effects of silica content on residual flexural strength of alumina-based ceramic core}

The residual flexural strength shows almost the same trend with room temperature flexural strength with the increase of silica content, as shown in Fig. 5. When the silica content is $4 \%$, the residual flexural strength is $50.30 \mathrm{MPa}$, then decreases to $47.41 \mathrm{MPa}$, increases again to $54.93 \mathrm{MPa}$, and decreases
The fracture morphologies of the specimens are shown in Fig. 7. The main fracture mechanism of the four samples is the breakage along the glass phase. Among them, intergranular fractures appear along the grain boundary of mullite phase in the SA-1, SA-2 and SA-3 samples. Much mullite phase is found in the glass phase in the SA-1, SA-2 and SA-3 samples, but the morphologies of the mullite are different. The mullite phase is block-like or short rod-like with a small length/diameter ratio in the SA-1 specimen, short pillar-like with a greater length/ diameter ratio in the SA-2 specimen, and dot-like in the SA-3 specimen. The SA-4 specimen mainly consists of the glass phase, and only a little dot-like mullite phase is found, because excessive silica leads to the formation of excessive glass phase.
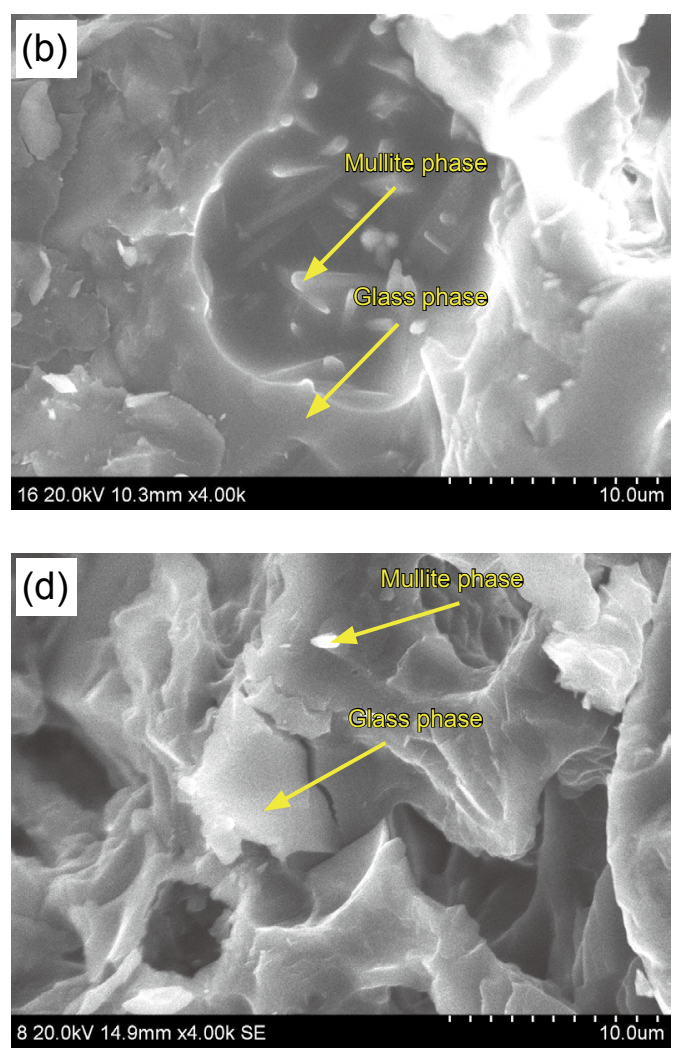

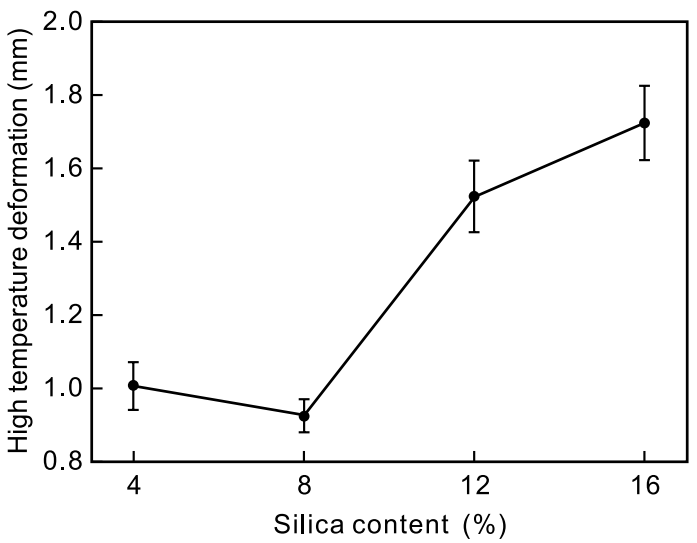

Fig. 8: High temperature deformation of ceramic cores 
again to $44.94 \mathrm{MPa}$ as the $\mathrm{Si}$ content further increases from $8 \%$ to $16 \%$. This indicates the silica content and residual flexural strength are not a simple linear relationship.

\subsection{Thermal expansion property of alumina-based ceramic core}

Thermal expansion property measuring was carried out for the SA-2 alumina-based ceramic core, and the results are shown in Fig. 9. The average linear expansion coefficient increases from $4.53 \times 10^{-6}{ }^{\circ} \mathrm{C}$ at $100{ }^{\circ} \mathrm{C}$ to $7.56 \times 10^{-6}{ }^{\circ} \mathrm{C}$ at $1,500{ }^{\circ} \mathrm{C}$. The linear expansion coefficient of the aluminabased ceramic core is close to that of the alumina-based ceramic shell mold ${ }^{[9-10]}$, which is helpful in reducing thermal stress in the shell mold.

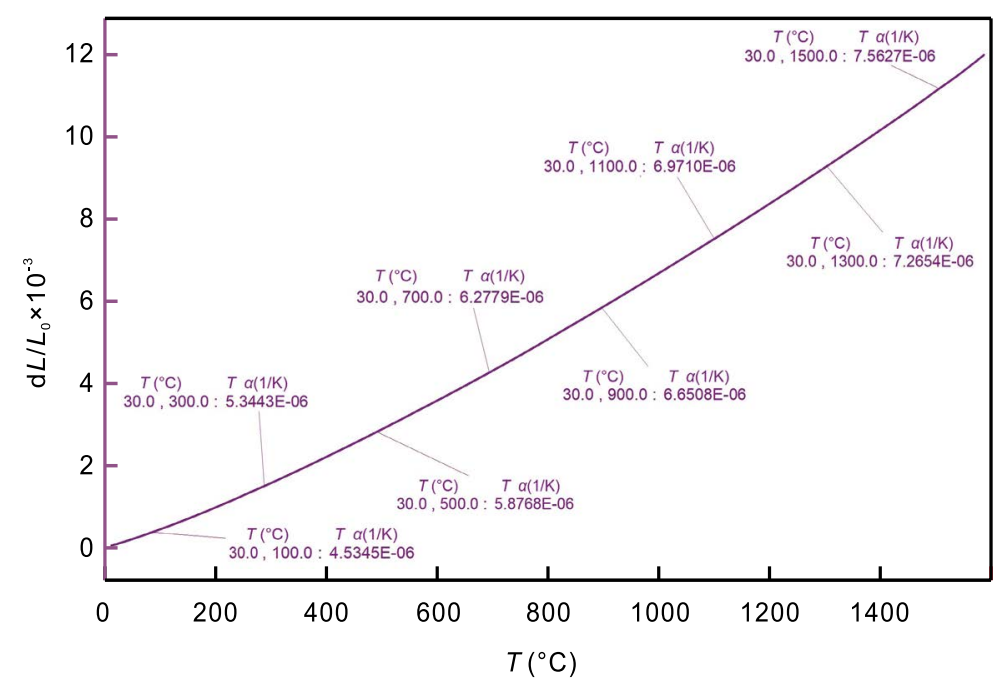

Fig. 9: Thermal expansion curve of SA-2 ceramic core

\subsection{Mineralization mechanisms of silica on alumina- based ceramic core}

The forming mechanisms of the mullite in the alumina-based ceramic core are basically the same with its thermodynamics and kinetics mechanisms in the alumina-based ceramic shell mold, reported by Liu and Xu et al. ${ }^{[1-12]}$, and the difference is that the silicon oxide in the shell mold is gelled amorphous, but granule-like crystal in the core. The binary, ternary or multi-element lowmelting-point eutectic mixture can be formed by the silica, the alumina, and other components during the sintering process, so, the sintering temperature of the alumina-based ceramics is greatly decreased. When a proper amount of liquid phase appears, the solid granules existing in the liquid phase can be wetted by the liquid phase. The working mechanism is that the wetting force and the surface tension of the liquid phase on the solid surface enable the solid granules to be close to each other, accelerating the dissolution of the $\mathrm{Al}^{3+}$ ions toward the silicon oxide, and promoting the formation of the mullite ${ }^{[13-15]}$.

A simultaneous thermal analysis was carried out for the SA-2 ceramic core, as shown in Fig.10. It can be found that the mass of the ceramic core almost does not change during the heating process, which conforms to the mass conservation law, and there is no low-volatile component in the core. A small endothermic peak inflection point at about $1,300{ }^{\circ} \mathrm{C}$ is found, indicating the mullite starts to form at this temperature. This is because there are a lot of lattice defects with higher activity in the fused corundum, decreasing the Gibbs free energy of the mullite reaction ${ }^{[16]}$.

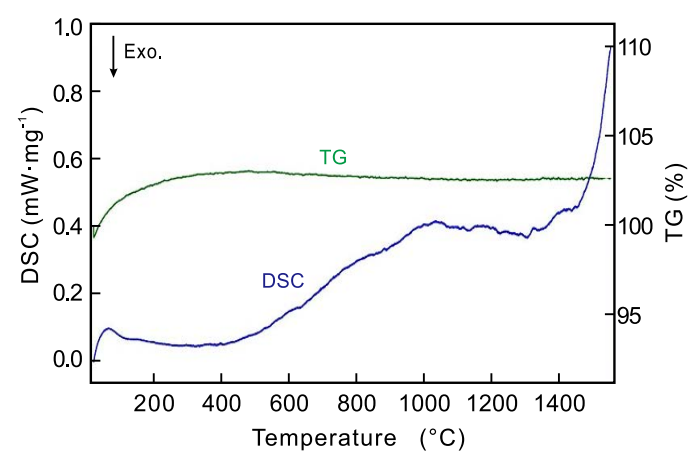

Fig. 10: STA curve of SA-2 alumina-based ceramic core

\section{Conclusions}

In this study, taking the fused corundum as matrix material, and the silica as mineralizer, the properties of the alumina-based ceramic cores were investigated, and the mineralizing mechanism was discussed. The following conclusions can be obtained:

(1) The sintering shrinkage coefficient of the alumina-based ceramic cores firstly decreases then increases with the increase of the silica contents. When the silica content is $8 \%$, the sintering shrinkage coefficient is the minimum of $0.66 \%$, and when the silica content is $16 \%$, the sintering shrinkage coefficient is the maximum of $1.01 \%$.

(2) The room temperature flexural strength and residual flexural strength of the alumina-based ceramic cores firstly decrease, then increase, and decrease again with the increase of the silica content. The high temperature flexural strength firstly increases and then decreases with the increase of the silica content, and the high temperature deformation firstly decreases and then increases with the increase of the silica content.

(3) The linear expansion coefficient increases linearly with the increase of temperature. The average linear expansion coefficient increases from $4.53 \times 10^{-6}{ }^{\circ} \mathrm{C}^{-1}$ at $100{ }^{\circ} \mathrm{C}$ to $7.56 \times 10^{-6}{ }^{\circ} \mathrm{C}^{-1}$ at $1,500{ }^{\circ} \mathrm{C}$.

(4) In this study, the optimum addition amount of the silica is $8 \%$. At this moment, the aluminumbased core has both a low sintering shrinkage coefficient of $0.66 \%$ and better properties: the room temperature flexural strength is $22.19 \mathrm{MPa}$, the high temperature flexural strength is $21.54 \mathrm{MPa}$, the high temperature deformation is $0.93 \mathrm{~mm}$, the residual flexural strength is $47.41 \mathrm{MPa}$.

\section{Acknowledgements}

This work was financially supported by the National Science and Technology Major Project of Aero Engine and Gas Turbine (2017-VII-0008). 


\section{References}

[1] Luo L, Xiao C B, Chen J Y, et al. Effect of directional solidification process on microstructure and stress rupture property of a hot corrosion resistant single crystal superalloy. China Foundry, 2019, 16(1): 8-13.

[2] Kulakov B A, Dubrovin V K and Znamenskii L G. Production of easily removable ceramic cores. Russian Castings Technology, 1997(4): 41-42.

[3] Bae C J. Integrally cored ceramic investment casting mold fabricated by ceramic stereolithography. Dissertation, Michigan: The University of Michigan, 2008: 1-2.

[4] Wereszczak A A, Breder K, Ferber M K, et al. Dimensional changes and creep of silica core ceramics used in investment casting of superalloys. Journal of Materials Science, 2002, 37(19): 4235-4245.

[5] Zhang Z B, Ma J S. Investigation report of Chinese investment foundry directors delegation visiting the US in 1998. Special Casting \& Nonferrous Alloys, 1999(1): 53-56. (In Chinese)

[6] Wang B S, Cheng L F, Zhang L T, et al. Study on core leach technic of alumina base ceramic core. Foundry, 2005, 54(8): 758-760. (In Chinese)

[7] Singh N P and Neubauer J M. Ceramic core for hollow investment castings. In: Proceedings of 50th Investment Casting Institute (ICl) Technical Meeting, Chicago, 2002.

[8] Bin Z, Wang L G, Yang G X. The effect of particle size on the properties of alumina-based ceramic core. Applied Mechanics and Materials, 2011, 79: 177-181.
[9] Liu X F, Lou Y C, Yu B, et al. Casting technologies of LMC method for directional solidification blades of heavy duty gas turbine. In: Proc. 2018 China Foundry Week, Suzhou, China, 2018.

[10] Li X, Liu X G,Yao J S, et al. Study on matching of silicon oxide core and corundum shell for hollow turbine blade of superalloy. In: Proc. 13th China Superalloy Annual Conference, Beijing, 2015.

[11] Liu X F. Research on alumina-based ceramic shell and core of directionally solidified heavy-duty gas turbine blades by liquid metal cooling. Doctoral dissertation, Shenyang: Shenyang Research Institute of Foundry Co., Ltd., 2015: 96-97.

[12] Xu Z L, Zhong J W, Su X L. Microstructure evolution and mechanical behaviors of alumina-based ceramic shell for directional solidification of turbine blades. Journal of Materials Research and Technology, 2019, 8(1): 876-886.

[13] Hotta $Y$, Banno T, Oda K. Physical properties of slip casting of high pure $\mathrm{Al}_{2} \mathrm{O}_{3}$ slurry using porous $\mathrm{Al}_{2} \mathrm{O}_{3}$-glass mold. Journal of Materials Science, 2002, 37: 417-423.

[14] Qin Y X, Pan W. Effect of silica sol on the properties of alumina-based ceramic core composites. Materials Science and Engineering A, 2009, 508(1): 71-75.

[15] Low I M, Lim F W, Low S S. Synthesis of highly leachable gelderived alumina ceramic cores. Journal of Materials Science Letters, 1993, 12(20): 1570-1573.

[16] Kleebe H J, Siegelin I F, Straubinger T. Conversion of $\mathrm{Al}_{2} \mathrm{O}_{3}$ $\mathrm{SiO}_{2}$ powder mixtures to mullite following the stable or metastable phase. Journal of the European Ceramic Society, 2001, 21(14): 2521-2533. 